\title{
COATING MATERIALS AS A POTENTIAL PRE-TREATMENTS FOR REDUCING OIL UPTAKE OF FRIED POTATO CHIPS
}

\author{
Saad Ahmed Saad Hallabo ${ }^{1}$, Mohamed Mohamed Ahmed El-Nikeety ${ }^{1}$, Samah Said Mahmoud Allam² \\ and Asmaa Gamal Abd El-hamied ${ }^{2 *}$ \\ ${ }^{I}$ Food Science Department, Faculty of Agriculture, Cairo University, Giza, Egypt \\ ${ }^{2}$ Oils and Fats Research Department, Food Technology Research Institute, Agricultural Research Center, Giza, Egypt \\ *asmaagamal2009@yahoo.com
}

https://doi.org/10.34302/2019.11.4.8

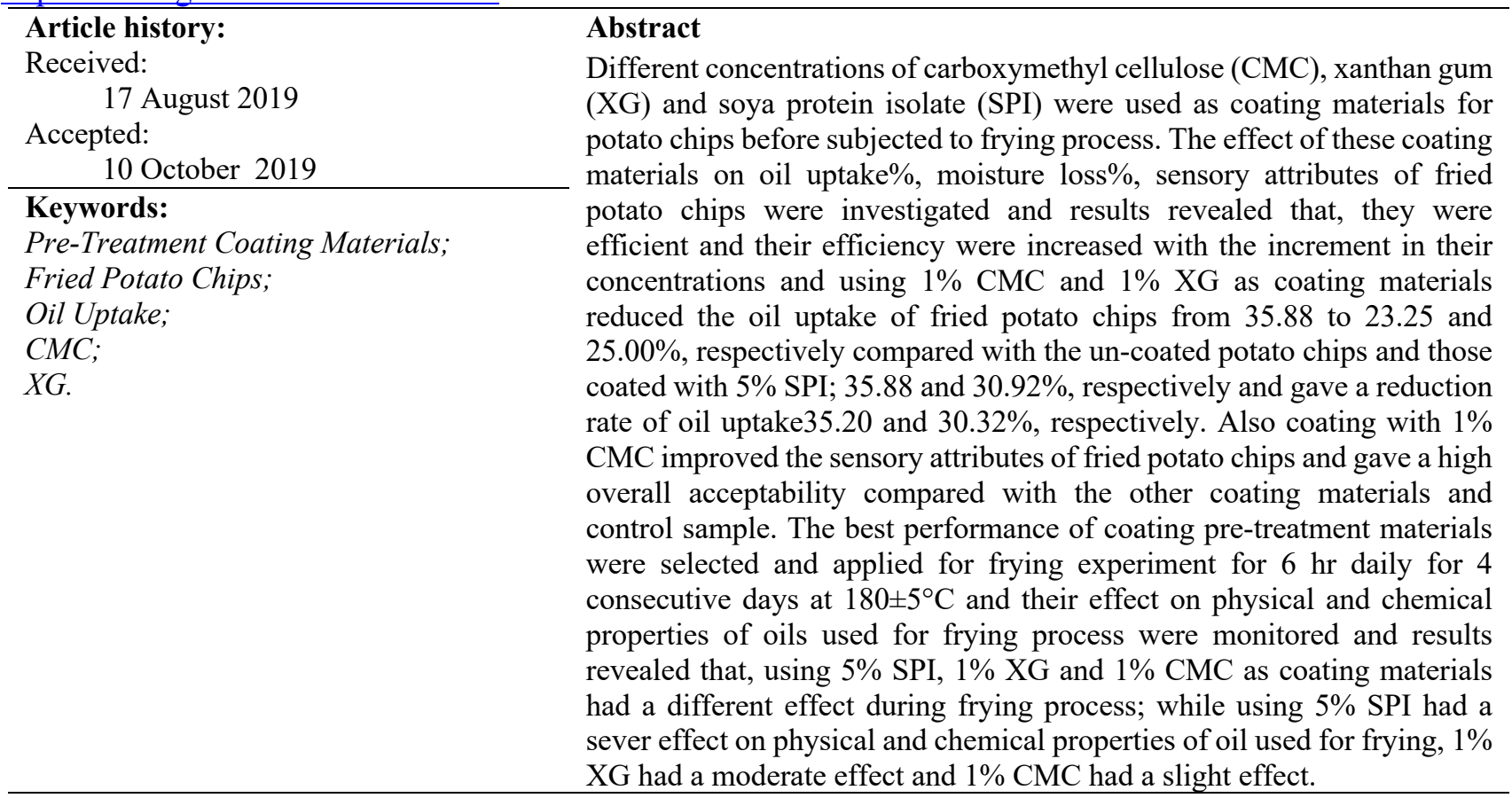

\section{Introduction}

Fried Potato chips are considered one of the most important products among all the snack food industry. During frying, the water present in the raw material evaporates, and is partially replaced by oil, constituting up to $40 \%$ of the finished product, and consequently affecting its properties (Lin Yu et al., 2016). As a result, consumption of deep-fat fried foods has been associated with coronary heart diseases, obesity and type 2 diabetes. Selection of an appropriate food coating before frying may act as a barrier to moisture loss, which is important commercially, and also reduce fat uptake during frying. (Ananey-Obiri et al., 2018).

During frying, the water loss process passes three different steps. The first step corresponds to potato heating, involving mainly the loss of water at the cutting surfaces. During the second step, an intense formation of water bubbles and an exponential decrease of water content with time are occurring. The third step occurs after the formation of the crust, hindering the movement of the vapor bubbles, created by the internal gas pressure (Costa 
et al., 1996). Physical changes induces by frying process such as crust formation have been closely correlated to oil penetration, and this imparts the characteristic appetizing nature of the food. Also fried foods develop desirable organoleptic properties such as color, crispiness, texture, and fried flavor resulting in popularity among consumers (Kassama and Ngadi, 2016).

Absorption of oil is influenced by a variety of factors; oil quality, product and frying temperature, oil degradation, frying time, frying duration, initial moisture content of food ingredients, product shape and content, porosity of coating, and the method of frying (Bouchon et al., 2003; Mellema, 2003; Math et al., 2004; Bouaziz et al., 2016).

Coating materials; protein based and polysaccharides based can be successfully used in food products as base components, alone or in a mixture. These materials have function properties such as thickening, gelling, stabilizing, film forming, dispersing and texture modifying (Kurek et al., 2017).

Coating agents is one of the effective methods used to reduce oil absorption in fried products and can be used as an alternative solution to comply with both health concerns and consumer preferences (Angor, 2016). The effectiveness of a coating material is determined by its mechanical and barrier properties, which depend on its composition and microstructure, and by the characteristics of the food product to which it binds. Hydrophilic biopolymers can be used as water binders in coating to reduce water loss from the coat. If we would be able to reduce water loss, oil uptake would also be reduced. Most commercial biopolymer coatings that are claimed to act like this to reduce fat uptake, are polysaccharide coatings (Sobowale and Omotoso, 2018).On the other hand, coating material can be used as emulsifiers in composite films, the surface tension between the oil and the food could also be reduced, consequently contributed to decrease oil uptake (Skurtys et al., 2010).

The objective of this study was to investigate the effects of pre-treatment agents such as; soya protein isolate (SPI), carboxy methyl cellulose $(\mathrm{CMC})$ and xanthan gum $(\mathrm{XG})$ on the oil uptake\%, moisture content $\%$, sensory attributes of fried potato chips and the quality characteristics of oil used for deep frying different pre-treatments coated potato chips compared with the un-coated potato chips (control sample) for $24 \mathrm{hr}$ at $180 \pm 5^{\circ} \mathrm{C}$.

\section{Materials and methods \\ 2.1.Materials}

Potatoes (Rosetta or Red variety) were purchased from the local market, Giza, Egypt. Refined, bleached and deodorized (RBD) sunflower oil free of added antioxidants was obtained from Arma Company, $10^{\text {th }}$ of Ramadan, Sharkia Governorate, Egypt. Carboxymethyl cellulose (CMC), xanthan gum (XG) and soya protein isolate (SPI) were purchased from Loba Chemie, India. Chemicals and solvents of analytical grade were purchased from ElGomheriya Company for Chemical and Drugs, Egypt.

\subsection{Methods}

Potatoes were washed, peeled and cut into chips with $1.5 \pm 0.1 \mathrm{~mm}$ thickness using a manual slicing machine and divided into portions.

Coating solutions were prepared for each coating material with different concentrations; 5, $10 \%$ of SPI, $0.5,1 \%$ of CMC and $0.5,1 \%$ of XG in distilled water. Each solution was heated to $90^{\circ} \mathrm{C}$ for 5 min with continuous stirring and cooled to room temperature. Each portion of potato chips was immersed for 30 seconds in one of the prepared coating solution with a ratio of $2: 1(\mathrm{wt} / \mathrm{vol})$ followed by air drying for $3 \mathrm{~min}$. The last portion of potato chips was treated in the same procedure without using coating materials (control sample).

Frying process: Three kilograms of sunflower oil with (6.50\% Palmitic acid, 3.50\% Stearic acid, $26.20 \%$ Oleic acid and $62.26 \%$ Linoleic acid) were used in deep fat frying process which was carried out for the 6 pre-treatments potato chips and potato chips without treatment (control sample) using a domestic fryer (Model 7122 A, tefal super 500 delux, France) in batches with a ratio of 1:30 potato weight/oil volume. Each batch lasted for $3 \mathrm{~min}$ at $180 \pm 5^{\circ} \mathrm{C}$. Frying different pre-treatments and control sample were lasted for $6 \mathrm{hr}$ daily for 4 
consecutive days without replenishment and $100 \mathrm{ml}$ of oil was withdrawn at the end of frying day and after oil was let to call down to room temperature, they stored in dark glass bottles at $-4{ }^{\circ} \mathrm{C}$ till analysis.

Moisture content $\%$ and oil uptake $\%$ of potato chips samples, refractive index $(\mathrm{RI})$ at $25^{\circ} \mathrm{C}$, free fatty acids (FFA) \% (as oleic acid) and peroxide value (PV) (meq $\mathrm{O}_{2} / \mathrm{kg}$ oil) were determined according to the method described by the AOAC (2016).

Fried potato chips (coated and un-coated) were evaluated by twenty panelists for sensory evaluation in terms of appearance, color, flavor, taste, crispiness and overall acceptability. Panelists were requested to assess each coded sample, and record the degree of difference using a 10-points Hedonic scale. On this scale, 1 represented dislike extremely and 10 represented like extremely (Singthong and Thongkaew, 2009). Results were statistically analyzed using CoState statistical software (CoHort Software, Monterey, CA, USA). The statistical calculations included the analysis of variance (ANOVA) one way completely randomized. $\mathrm{P}<0.05$ was considered to be significant using Duncan's test. All data were expressed as means values \pm Standard Deviation (SD), as described by Snedecor and Cochran (1982).

Fatty acids were carried out by preparation of methyl ester followed by the identification of methyl esters using an Agilent 6890 series gas chromatograph apparatus equipped with a DB23 (60 m X 0.32) (ISO, 2011).

Color of oil samples was measured by using a Lovibond Tintometer model F, 5.25 inch cell and expressed as total color $5 \times$ red $+1 \times$ yellow Lovibond units according to (Latha and Nasirullah, 2014).

Polymer contents (PC) \% of oil samples were determined following the method mentioned by Pel-Fan and Nawar (1986).Total polar compounds (TPC) \% of oil samples were determined by using the column chromatography method described by (Waltking and Wessels, 1981).

Viscosity (cP) was monitored using Brookfiled Viscometer RVDV Spindle SC4-21 connected to water bath Brook-field TC500. Viscosity determination was carried out at $25 \pm 0.1{ }^{\circ} \mathrm{C}$ according to the method described by Howard (1991).

\section{Results and discussion}

\subsection{Influence of coating materials on moisture loss and oil uptake\% of fried potato chips}

Data in Table (1) show the effect of coating materials on moisture content and oil uptake $\%$ of potato chips after being fried in sunflower oil at $180 \pm 5^{\circ} \mathrm{C}$ and data indicated that, potato chips immersed in $1 \% \mathrm{CMC}$ as edible coating material had the highest reduction rate $\%$ in oil absorption followed by potato chips treated with $1 \% \mathrm{XG}$ and those treated with $10 \% \mathrm{SPI} ; 35.20,30.32$ and $24.72 \%$, respectively. Results in Table (1) revealed that, increasing $\mathrm{CMC}, \mathrm{XG}$ and SPI concentrations were accompanied by decreasing the oil content of fried coated potato chips. The thermal gelation properties of coating materials led to the formation of a small amount of wide punctures with low capillary pressures, which resulted in less oil entrance to the pores as illustrated by (Mellema, 2003).

Table 1. Effects of coating pre-treatments on oil uptake $\%$ and moisture content $\%$ of fried potato chips

\begin{tabular}{|c|c|c|c|c|c|c|c|}
\hline \multirow{2}{*}{ Coating agents } & \multirow{2}{*}{ Un-coated } & $\mathbf{0 . 5 \%}$ & $\mathbf{1 \%}$ & $\mathbf{0 . 5 \%}$ & $\mathbf{1 \%}$ & $\mathbf{5 \%}$ & $\mathbf{1 0 \%}$ \\
\cline { 3 - 8 } & 35.88 & 26.31 & 23.25 & 28.85 & 25.00 & 30.92 & 27.01 \\
\hline Oil uptake \% & 0.00 & 26.37 & 35.20 & 19.59 & 30.32 & 13.82 & 24.72 \\
\hline $\begin{array}{c}\text { Oil uptake } \\
\text { reduction \% }\end{array}$ & 0.94 & 1.60 & 1.94 & 1.55 & 1.87 & 1.06 & 1.20 \\
\hline $\begin{array}{c}\text { Moisture } \\
\text { content\% }\end{array}$ & & & & & \\
\hline
\end{tabular}

CMC: carboxy methyl cellulose

$\mathrm{XG}$ : xanthan gum

SPI: soya protein isolate

Moisture content of fried potato chips was affected by coating agents; $0.5,1 \% \mathrm{CMC}, 0.5,1 \%$

$\mathrm{XG}$ and 5, 10\% SPI used as pre-treatments before frying process (Table 1). Moisture content of the 
control (un-coated) fried potato chips was found to be $0.94 \%$. The moisture content of fried samples was increased with the increase in the concentration of coating materials used. The highest moisture retention was found by using 1\% CMC (1.94\%), this positive effect could be related to the high water binding capacities of $\mathrm{CMC}$, preventing the replacement of moisture with oil during the frying process. Moisture loss and oil absorption have inverse relationship as previously reported by Bouaziz et al., (2016).

Hydrocolloids have been proved to reduce the oil uptake during the frying process as reported by several workers, Hua et al. (2015) observed the effectiveness of pectin in reducing oil uptake during frying of potato chips; Maity et al. (2015) found similar relationship between moisture loss and oil uptake in deep fat fried jackfruit chips coated with hydrocolloids and Bouaziz et al. (2016) also found minor oil uptake in fried potato chips treated with almond gum as coating agent during frying process.

\subsection{Effect of coating agents on sensory attributes of fried potato chips}

Sensory attributes of fried potato chips are presented in Table (2). High heat transfer rates during frying developed and improved desirable sensory properties of fried products (Hubbard and Farkas, 2000). Changes in sensory attributes of fried potato chips after coating could be attributed to the different behavior between coating materials and starch during frying (Hua et al., 2015). Fried potato chips coated with $1 \% \mathrm{CMC}$ had the highest scores in all sensory attributes and overall acceptability (with a significant difference $\mathrm{P}<0.05$ ), which suggested that fried coated potato chips may be more attractive than the un-coated one. The overall acceptability of potato chips coated with either $\mathrm{CMC}$ or $\mathrm{XG}$ was higher than those coated with SPI and there was an increase in sensory attributes of the coated potato chips with the increment of $\mathrm{CMC}$ and $\mathrm{XG}$ concentrations.

Fried products' color is one of the most important physical attribute that greatly influence consumer perception and can summarily lead to rejection of the product (Sobowale and Omotoso, 2018). The high color value was observed in fried potato chips coated with 1\% CMC and $1 \% \mathrm{XG}$ while the lowest value was obtained for potato chips coated with $10 \%$ SPI, the color development of SPI-coated potato chips may be attributed to the Maillard reaction occurred between reducing sugar and amino acid of the SPI coated potato chips. These results are in accordance with those reported by (Sobowale and Omotoso, 2018) in regarding the increment in sensory acceptability of potato chips coated with egg and carboxyl-methylcellulose. Also Kilincceker et al. (2009) reported that the smell, taste and flavor of the frozen fish fillets samples were improved by using coating materials compared to un-coated sample, and the desired color formed. On the other hand, Hua et al. (2015); Bouaziz et al. (2106) found that, the un-coated potato chips had the highest scores in all attributes and overall acceptance.

Table 2. Sensory evaluation of coated and un-coated fried potato chips

\begin{tabular}{|c|c|c|c|c|c|c|c|}
\hline \multirow{2}{*}{$\begin{array}{l}\text { Coating } \\
\text { agents } \\
\begin{array}{l}\text { Sensory } \\
\text { attributes }\end{array}\end{array}$} & \multirow[b]{2}{*}{ Un-coated } & \multicolumn{2}{|c|}{ CMC } & \multicolumn{2}{|c|}{ XG } & \multicolumn{2}{|c|}{ SPI } \\
\hline & & $0.5 \%$ & $1 \%$ & $0.5 \%$ & $1 \%$ & $5 \%$ & $10 \%$ \\
\hline Appearance & $7.70 \pm 0.9^{\mathrm{ab}}$ & $8.00 \pm 0.53^{\mathrm{ab}}$ & $8.80 \pm 0.53^{\mathrm{a}}$ & $7.30 \pm 0.65^{\mathrm{a}}$ & $7.50 \pm 0.74^{\mathrm{ab}}$ & $6.80 \pm 0.93^{\mathrm{b}}$ & $6.30 \pm 1.55^{\mathrm{b}}$ \\
\hline Color & $8.00 \pm 0.52^{\mathrm{ab}}$ & $8.00 \pm 0.73^{\mathrm{ab}}$ & $9.00 \pm 0.21^{\mathrm{a}}$ & $8.50 \pm 0.84^{\mathrm{ab}}$ & $8.70 \pm 0.91^{\mathrm{a}}$ & $7.20 \pm 0.63^{\mathrm{bc}}$ & $6.20 \pm 0.83^{\mathrm{c}}$ \\
\hline Flavor & $8.00 \pm 0.50^{\mathrm{a}}$ & $8.00 \pm 0.2^{\mathrm{ab}}$ & $8.50 \pm 1.00^{\mathrm{a}}$ & $7.20 \pm 0.30^{\mathrm{ab}}$ & $7.50 \pm 1.00 \mathrm{a}^{\mathrm{b}}$ & $7.23 \pm 0.3^{\mathrm{b}}$ & $7.00 \pm 0.40^{\mathrm{b}}$ \\
\hline Taste & $7.80 \pm 0.20^{\mathrm{b}}$ & $8.20 \pm 0.30^{\mathrm{ab}}$ & $8.50 \pm 0.10^{\mathrm{a}}$ & $7.60 \pm 0.30^{\mathrm{b}}$ & $7.80 \pm 0.10^{b}$ & $7.00 \pm 0.50^{\mathrm{c}}$ & $7.00 \pm 0.50^{c}$ \\
\hline Crispiness & $7.93 \pm 0.4^{\mathrm{ab}}$ & $8.10 \pm 0.20^{\mathrm{ab}}$ & $8.50 \pm 0.70^{b}$ & $7.50 \pm 0.5^{\mathrm{b}}$ & $7.80 \pm 0.30^{\mathrm{ab}}$ & $7.56 \pm 0.40^{\mathrm{ab}}$ & $7.50 \pm 0.30^{\mathrm{ab}}$ \\
\hline $\begin{array}{c}\text { Overall } \\
\text { Acceptability }\end{array}$ & $8.50 \pm 0.20^{\mathrm{ab}}$ & $8.00 \pm 0.20^{c}$ & $8.70 \pm 0.10^{\mathrm{a}}$ & $8.30 \pm 0.10^{b c}$ & $8.00 \pm 0.10^{\mathrm{c}}$ & $7.00 \pm 0.20^{\mathrm{d}}$ & $6.50 \pm 0.30^{\mathrm{e}}$ \\
\hline
\end{tabular}

Means \pm SD. values in the same row with different superscript letters are significantly different $(\mathrm{p}<0.05)$ 


\subsection{Effect of using coating materials on the physical and chemical characteristics of oil used in frying process}

Frying experiment was conducted using potato chips coated with coating materials in concentrations that gave the best performance in reducing oil uptake\% and have a high over all acceptability by panelist compared with the uncoated potato chips (control sample).

Accordingly, potato chips coated with 1\% $\mathrm{CMC}$, potato chips coated with $1 \% \mathrm{XG}$ and those coated with 5\% SPI were selected for frying process for $6 \mathrm{hr}$ daily for 4 consecutive days.

Frying oils' properties were affected by various frying conditions; temperature, time and the nature of fried products. Changes in these properties were monitored and results were tabulated in Tables $(3,4)$.

The effect of frying conditions and coating materials on the physical properties (refractive index $\{\mathrm{RI}\}$, viscosity and total color) of oils used for frying at $180 \pm 5^{\circ} \mathrm{C}$ for $24 \mathrm{hr}$ (six hr per day for four consecutive days) are shown in Table (3). Data in Table (3) illustrated that, during frying process, RI, viscosity and total color were increased as frying time increased, and there were a gradually increased in both RI and viscosity, while the total color had different trend as they was sharply increased after frying for $12 \mathrm{hr}$ and then gradually increased through the last $12 \mathrm{hr}$ of frying both uncoated and coated potato chips with different coating materials. The increments of RI, viscosity and total color were more pronounced with oils used for frying the un-coated potato chips and potato chips coated with 5\% SPI rather than oils used for frying potato chips coated with either $1 \%$ $\mathrm{CMC}$ or $1 \% \mathrm{XG}$ throughout the $24 \mathrm{hr}$ of frying process.

The effect of frying conditions and coating agents on the chemical characteristics (free fatty acids $\{\mathrm{FFA}\}$ ( $\%$ as oleic acids), peroxide values $\{\mathrm{PV}\}$ (meq $\mathrm{O}_{2} / \mathrm{kg}$ oil), polymer content $\{\mathrm{PC}\} \%$ and total polar compounds $\{\mathrm{TPC}\} \%$ ) of oils used in frying process were monitored and results were tabulated in Table (4).

Table 3. Physical characteristics of oils used in frying coated and un-coated potato chips at $180 \pm 5^{\circ} \mathrm{C}$ for $24 \mathrm{hr}$ (4 consecutive days)

\begin{tabular}{|c|c|c|c|c|}
\hline Pre-treatment & Frying time (hr) & $\begin{array}{c}\text { Refractive index } \\
\left(\mathbf{a t}_{\mathbf{2 5}}^{\mathbf{C}} \mathbf{)}\right.\end{array}$ & $\begin{array}{c}\text { Viscosity } \\
\mathbf{( c P )}\end{array}$ & Total color \\
\hline Fresh oil & $\mathbf{0}$ & 1.4730 & 59.00 & 7.0 \\
\hline \multirow{3}{*}{ Un-coated } & $\mathbf{6}$ & 1.4739 & 61.50 & 11.5 \\
\cline { 2 - 5 } & $\mathbf{1 2}$ & 1.4750 & 65.00 & 40.0 \\
\cline { 2 - 5 } & $\mathbf{1 8}$ & 1.4762 & 72.00 & 65.0 \\
\hline \multirow{3}{*}{ Coated with 1\% CMC } & $\mathbf{2 4}$ & 1.4776 & 79.00 & 100.0 \\
\cline { 2 - 5 } & $\mathbf{6}$ & 1.4737 & 61.00 & 11.0 \\
\cline { 2 - 5 } & $\mathbf{1 2}$ & 1.4743 & 63.50 & 68.0 \\
\hline \multirow{3}{*}{ Coated with 1\% XG } & $\mathbf{1 8}$ & 1.4452 & 67.91 & 90.0 \\
\cline { 2 - 5 } & $\mathbf{2 4}$ & 1.4770 & 75.64 & 11.5 \\
\cline { 2 - 5 } & $\mathbf{6}$ & 1.4738 & 61.24 & 60.0 \\
\cline { 2 - 5 } & $\mathbf{1 2}$ & 1.4747 & 64.00 & 96.0 \\
\hline \multirow{3}{*}{ Coated with 5\% SPI } & $\mathbf{1 8}$ & 1.4758 & 68.45 & 12.0 \\
\cline { 2 - 5 } & $\mathbf{6}$ & 1.4773 & 76.25 & 49.0 \\
\cline { 2 - 5 } & $\mathbf{1 2}$ & 1.4741 & 63.00 & 73.0 \\
\cline { 2 - 5 } & $\mathbf{1 8}$ & 1.4770 & 66.00 & 112.0 \\
\hline
\end{tabular}


Table 4. Chemical characteristics of oils used in frying coated and un-coated potato chips at $180 \pm 5^{\circ} \mathrm{C}$ for $24 \mathrm{hr}$ (4 consecutive days)

\begin{tabular}{|c|c|c|c|c|c|}
\hline Pre-treatment & $\begin{array}{c}\text { Frying time } \\
\text { (hr) }\end{array}$ & $\begin{array}{c}\text { Free fatty acids } \\
\text { (\% as oleic acids) }\end{array}$ & $\begin{array}{l}\text { Peroxide value } \\
\left.\text { (meq } \mathrm{O}_{2} / \mathrm{kg} \text { oil }\right)\end{array}$ & $\begin{array}{c}\text { Polymer } \\
\text { contents \% }\end{array}$ & $\begin{array}{c}\text { Total polar } \\
\text { Compounds \% }\end{array}$ \\
\hline Fresh oil & 0 & 0.06 & 1.19 & 0.00 & 2.55 \\
\hline \multirow{4}{*}{ Un-coated } & 6 & 0.30 & 4.10 & 1.05 & 10.53 \\
\hline & 12 & 0.57 & 10.60 & 2.25 & 18.37 \\
\hline & 18 & 0.89 & 16.10 & 3.85 & 22.11 \\
\hline & 24 & 1.18 & 25.13 & 7.08 & 27.50 \\
\hline \multirow{4}{*}{ Coated with $1 \% \mathrm{CMC}$} & 6 & 0.23 & 3.92 & 0.90 & 9.85 \\
\hline & 12 & 0.46 & 9.18 & 2.19 & 17.92 \\
\hline & 18 & 0.85 & 14.37 & 3.60 & 20.78 \\
\hline & 24 & 1.03 & 23.09 & 6.72 & 25.52 \\
\hline \multirow{4}{*}{ Coated with $1 \%$ XG } & 6 & 0.31 & 4.20 & 0.94 & 10.24 \\
\hline & 12 & 0.55 & 9.78 & 2.27 & 18.10 \\
\hline & 18 & 0.91 & 15.23 & 3.69 & 21.94 \\
\hline & 24 & 1.12 & 24.38 & 6.84 & 26.98 \\
\hline \multirow{4}{*}{ Coated with 5\% SPI } & 6 & 0.53 & 5.93 & 1.70 & 17.00 \\
\hline & 12 & 0.76 & 13.42 & 3.21 & 26.21 \\
\hline & 18 & 1.17 & 18.60 & 4.31 & 30.09 \\
\hline & 24 & 1.49 & 16.70 & 8.21 & 35.52 \\
\hline
\end{tabular}

Results in the same Table revealed that, FFA\% were sharply increased throughout the first $6 \mathrm{hr}$ of frying the un-coated and coated potato chips with different coating materials and after that they were gradually increased during the rest of frying hours till the end of frying time; $24 \mathrm{hr}$. This sharp increment was very obvious when frying potato chips coated with 5\% SPI followed by un-coated potato chips and potato chips coated with $1 \% \mathrm{XG}$ (1.49, 1.18 and 1.12 , respectively) and the least affect was shown when frying potato chips coated with $1 \%$ CMC (1.03).

This trend of increment was also noticed when monitoring the changes in $\mathrm{PC} \%$ for oils used in our frying experiment, regarding the sharp increase in PC $\%$ during the first 6 hours followed by gradually increase during the rest of the experiment time (24 hr). Also, these changes in $\mathrm{PC} \%$ were more pronounced in oils used for frying potato chips coated with $5 \%$ SPI followed by un-coated potato chips and potato chips coated with $1 \%$ XG (8.21, 7.08 and 6.84, respectively). Polymers are mainly responsible for the increase in viscosity, refractive index, specific gravity and contribute to the foaming tendency of heated oil (Wang et al., 2016). From Table (4) we can also noticed that PV, which was used as a measurement of the primary products of oxidation, was monitored for oil samples used in frying process and the tabulated results in Table (4) illustrated that PV of oils used in frying were increased sharply after $6 \mathrm{hr}$ of frying either untreated or pre-treated potato chips with different coating materials and these were more pronounced when frying potato chips coated with $5 \%$ SPI, followed by potato chips coated with $1 \% \mathrm{XG}$ and un-coated potato chips (5.93, 4.20 and $4.10 \mathrm{meq}$ $\mathrm{O}_{2} / \mathrm{kg}$ oil, respectively). Also, we could observed that PV of all oil samples had the same trend as the previously mentioned chemical characteristics; FFA \% and PC\% with one exception that PV of oil used for frying 5\% SPI coated potato chips had declined in the last 6 hours of frying process from 18.60 to $16.70 \mathrm{meq} \mathrm{O}_{2} / \mathrm{kg}$ oil at the end of frying time $24 \mathrm{hr}$. Peroxides are unstable and can break down to carbonyl and aldehydic compounds as a result of secondary oxidation (Li et al., 2014). These data are in agreement with those reported by (Khazaei et al., 2016), who indicated that, the coating treatment was effective in reducing lipid oxidation and as previously stated by Kim et al. (2011), hydrocolloid coatings significantly reduced the heat transfer coefficients as well as oil uptake, which could be contributed to the lower lipid oxidation in the coated fried food compared to un- 
coated (control) samples. In parallel, Aminlari et al. (2005) found that potato chips coated with sodium caseinate had $14 \%$ less oil than control samples. In coated chips the water retention and the protein content was significantly increased, and the peroxide value was decreased between $30 \%$ and $50 \%$.

Total polar compounds\% (TPC) of oils which indicates the total amount of degradation compounds in frying oils were also determined and results were tabulated in Table (4). Results showed that, coating potato chips with 5\% SPI had severally affected the TPC\% of oils used in frying process when compared with oils used for frying un-coated potato chips, potato chips coated with $1 \% \mathrm{XG}$ and those coated with 1\% CMC; 35.52, 27.50, 26.98 and 25.52 , respectively.

From Tables $(3,4)$ we could observed that frying potato chips coated with $1 \% \mathrm{CMC}$ slightly affect the physical and chemical characteristics of oil used for frying for $24 \mathrm{hr}$ at $180 \pm 5^{\circ} \mathrm{C}$ compared with the other coating materials and control sample without coating.

\section{Conclusions}

Coating as a pre-treatment procedure was important for fried food manufacture in reducing the oil uptake of fried potato chips. The oil uptake had a reciprocal relationship with the moisture content retained in the fried potato chips. Using $1 \%$ $\mathrm{CMC}$ as an edible coating material was more effective in reducing oil uptake $\%$ and improved the sensory attributes of fried potato chips compared with the other coating materials with different concentrations used in our experiment and slightly affected the physical and chemical properties of oil used for frying at $180 \pm 5^{\circ} \mathrm{C}$ for $24 \mathrm{hr}$.

Although, SPI was effective in reducing oil uptake $\%$ and increasing its concentration was accompanied by increasing its efficiency in oil uptake reduction rate, it was severally affected the physical and chemical characteristics of oils used in frying process and can't be practically used in commercial scale.

So, during frying process coating pretreatments could be used in decreasing the oil uptake $\%$ while maintaining the high quality of the fried potato chips which would be benefit for the consumer, adding value to the snake market as a healthy food product and CMC could be used as a potential coating material in reducing oil uptake of fried potato chips during frying process.

\section{References}

Aminlari, M., Ramezani, R., Khalili, M. H. (2005). Production of protein-coated low-fat potato chips. Food Science and Technology International, 11(3), 177-181.

Ananey-Obiri, D., Matthews, L., Azahrani, M. H., Ibrahim, S. A., Galanakis, C. M., Tahergorabi, R. (2018). Application of protein-based edible coatings for fat uptake reduction in deep-fat fried foods with an emphasis on muscle food proteins. Trends in Food Science and Technology, (80), 167-174.

Angor, M. M. (2016). Reducing fat content of fried potato pellet chips using carboxymethyl cellulose and soya protein isolate solutions as coating films. Journal of Agricultural Science, 8(3), 168-168.

AOAC (2016). Official Methods of Analysis of AOAC International $20^{\text {th }} \mathrm{Ed}$. Association of Official Analytical Chemists, Gaithersburg, Maryland. U.S.A.

Bouaziz, F., Koubaa, M., Neifar, M., ZouariEllouzi, S., Besbes, S., Chaari, F., Kamoun, A., Chaabouni, M., Chaabouni, S. E, Ghorbel, R. E. (2016). Feasibility of using almond gum as coating agent to improve the quality of fried potato chips: Evaluation of sensorial properties. LWT-Food Science and Technology, (65), 800807.

Bouchon, P., Aguilera, J. M., Pyle, D. L. (2003). Structure oil absorption relationships during deep-fat frying, Journal of Food Science, 68(9), 2711-2716.

Costa, R. M., Oliveira, F. A. R., Gekas, V. (1996). Water loss during frying of thin potato slices. In The first main meeting of process optimisation and minimal processing of foods. Porto: Escola Superior de Biotecnologia, (3), 70-75.

Howard, D.W. (1991). A look at viscometry. Food Technol., 82-84.

Hua, X., Wang, K., Yang, R., Kang, J., Yang, H. 
(2015). Edible coatings from sunflower head pectin to reduce lipid uptake in fried potato chips. LWT-Food Science and Technology, (62), 1220-1225.

Hubbard, L. J., Farkas, B. E. (2000). Influence of oil temperature on heat transfer during immersion frying. Food Process J. Preserv, (24), 143-162.

ISO (12966-2/2011). International standard. Animal and vegetables fats and oil preparation of methyl esters of fatty acids.

Kassama, L. S., Ngadi, M. (2016). Relationship between oil uptake and moisture loss during deep fat frying of deboned chicken breast meat. Advances in Chemical Engineering and Science, 6(04), 324-334.

Khazaei, N., Esmailli. M., Emam-Djomeh, Z. (2016). Effect of active edible coatings made by basil seed gum and thymol on oil uptake and oxidation in shrimp during deep-fat frying, Carbohydrate polymer, (137), 249-254

Kilincceker, O., Dogan, I., Kucukoner, E. (2009). Effect of edible coatings on the quality of frozen fish fillets. $L W T$ - Food Science and Technology, (42), 868- 873.

Kim, D. N., Lima, J. Bae, I. Y., Lee, H.G., Lee, S., (2011). Effect of hydrocolloid coatings on the heat transfer and oil uptake during frying of potato strips. Journal of Food Engineering, (102), 317-320.

Kurek, M., Scetar, M., Gali, K. (2017). Edible coatings minimize fat uptake in deep fat fried products: Areview. Food Hydrocolloids, (71), 225-235.

Latha, R. B., Nasirullah, D. R. (2014). Physicochemical changes in rice bran oil during heating at frying temperature. J. Food Science and Technology, 51(2), 335-340.

Li, y., Ma, w., Qi, B., Rokayya, S., Li, D., Wang, J., Feng, H., Sui, H., Jiang, L. (2014). Blending of soybean oil with selected vegetable oils: impact on oxidative stability and radical scavenging activity. Asian Pacific Journal of Cancer Prevention, (15), 2583-2589.

Lin Yu, Jinwei, L. I., Ding, S., Hang, F., d Fan, L. (2016). Effect of guar gum with glycerol coating on the properties and oil absorption of fried potato chips. Food Hydrocolloids, (54), 211-219.

Maity, T., Bawa, A. S., Raju, P. S. (2015). Use of hydrocolloids to improve the quality of vacuum fried jackfruit chips. International Food Research Journal, 22(4), 1571-1577.

Math, R. G., Velu, V., Nagender, A., Rao, D. G. (2004). Effect of frying conditions on moisture, fat, and density of papad. Journal of Food Engineering, 64(4), 429-434.

Mellema, M. (2003). Mechanism and reduction of fat uptake in deep-fat fried foods. Trends in Food Science and Technology, (14), 364-373.

Pel-Fan, W., Nawar, W. W. (1986). A technique for monitoring the quality of used frying oils. $J$. Am. Oil Chem. Soc., (63), 1363- 1367.

Singthong, J., Thongkaew, C. (2009). Using hydrocolloids to decrease oil absorption in banana chips. LWT-Food Science and Technology, 42(7), 1199-1203.

Skurtys, O., Acevedo, C., Pedreshi, F., Enrione, J., Osorio, F., Aguilera, J. M. (2010). Food hydrocolloid edible films and coatings. New York: Nova Science Publishers Inc.

Snedecor, G. W., Cochran, W. G. (1982). Statistical methods. $6^{\text {th }}$ ed., lowa State Univ., Press, lowa, U.S.A.

Sobowale, S. S., Omotoso, B.O. (2018). Effect of pre-drying and hydrocolloids batter coating during heat and moisture transfer of coated fried potato chips. Journal of Bioprocessing \&Biotechniques, (8), 1-9.

Waltking, A. E., Wessels, H. (1981). Chromatographic separation of polar and non polar components of frying fats. J. Assoc. of Chem., (64) 1329-1330.

Wang, S. N., Sui, X. N., Wang, Z. J., Qi, B. K., Jiang, L. Z., Li, Y. (2016). Improvement in thermal stability of soybean oil by blending with camellia oil during deep fat frying. European Journal of Lipid Science and Technology, (118), 524-531. 